\title{
Clinical characteristics and outcomes of patients with small cell lung
}

\section{cancer detected by CT screening}

Toshirou Fukushima ${ }^{1)}$, Kazunari Tateishi ${ }^{1)}$, Shintarou Kanda ${ }^{1)}$,

Hiroshi Yamamoto ${ }^{1)}$, Masayuki Hanaoka ${ }^{1)}$, Keishi Kubo ${ }^{1)}$, Tomonobu Koizumi ${ }^{2)}$

1) First Department of Internal Medicine, and ${ }^{2)}$ Department of Comprehensive

Cancer Therapy, Shinshu University School of Medicine, 3-1-1 Asahi Matsumoto,

Nagano, 390-8621, Japan.

Corresponding Author: Tomonobu Koizumi, MD, PhD.

Department of Comprehensive Cancer Therapy, Shinshu University School of

Medicine, 3-1-1 Asahi Matsumoto, Nagano, 390-8621, Japan.

Phone: +81-263-37-2554

Fax: $+81-263-37-3302$

Email: tomonobu@shinshu-u.ac.jp 
Abstract

Objective The present study was performed to evaluate the clinical characteristics and survival outcomes in patients with small cell lung cancer (SCLC) detected by low-dose computed tomography (CT). Methods We retrospectively reviewed clinical records of patients with SCLC treated at our hospital between 1997 and 2011 and selected patients with SCLC detected by CT screening. Results We identified 12 patients (male/female: 11/1; mean age: 67.8 years old. Nine patients had limited disease (LD) and 3 had extensive disease (ED). Five LD patients underwent thoracic surgery and the pathological staging information included stage IA $(n=1)$, IB $(n=1)$, IIA $(n=1)$, and IIIB $(n=2)$. Although 2 patients with pathological stages IA and IB had > 10-year survival, the median survival times (MST) in LD and ED were 25 months (95\% CI; $17.0-32.9)$ and 16 months (95\% CI; not evaluated), respectively. In addition, MST in 12 patients was not significantly different from that in SCLC patients in general care in our hospital. Conclusions This analysis suggested that CT screening contributes to the detection of early-stage SCLC in patients that are potentially suitable for surgery, but it 
remains unclear how to improve clinical outcome in patients with SCLC.

Key words: LD-SCLC, chemotherapy, CT screening, lung cancer surveillance 


\section{Introduction}

Lung cancer is the leading cause of cancer mortality worldwide [1], including Japan [2]. Small cell lung cancer (SCLC) represents $10 \%-15 \%$ of all lung cancers [2,3] and shows a high grade of malignancy with rapid growth and early widespread metastasis. As SCLC is a virulent disease with high metastatic potential, SCLC is usually considered a systemic disease at initial presentation. There have been many reports that chest computed tomography (CT) can detect more of these lesions at an earlier stage than chest radiography[4,5]. The National Lung Screening Trial (NLST), a large randomized controlled trial designed to evaluate low-dose computed tomography (CT) screening for lung cancer in heavy smokers, demonstrated a decrease in lung cancer-specific mortality in a CT screening population[6,7]. We also initially began a low-dose CT screening trial using a mobile CT unit [8 - 10], and previously demonstrated in Japanese smokers that CT screened lung cancer patients had a better survival rate than those that were non-screened [10]. Multivariate analysis in the NLST [6] and our data [10] indicated survival benefit by CT screening mainly in adenocarcinoma. Recently, Cuffe et al. [11] retrospectively reviewed 10 SCLC patients who were diagnosed during two low-dose CT lung cancer screening programs. They reported that the clinical stage and survival were identical to those in clinical practice, suggesting ineffectiveness of CT screening for SCLC. However, there have been few reports focusing on screening-detected SCLC. In the present study, to determine the clinical characteristics, treatment, and survival outcomes in patients detected by 
CT screening, we performed a retrospective review of SCLC patients treated at our institute.

\section{Patients and Methods}

Between January 1997 and December 2011, a total of 148 cases of SCLC were admitted to the Respiratory Center, Shinshu University Hospital. Among them, 12 cases of SCLC $(8.1 \%)$ were detected by CT screening. The study subjects were identified and selected retrospectively from the hospital electronic clinical record search engine. Patient privacy was protected when using individual information. Cases of large cell neuroendocrine carcinoma or mixed with non-SCLC were excluded from the present analysis.

The interpretation of CT images was based on commonly used imaging features, i.e., morphological characteristics and interval growing tendency $[12,13]$. When abnormal findings were found on the initial CT (baseline), routine fiberscopic bronchoscopy combined with transbronchial needle aspiration, forceps biopsy, brushing and washing, or percutaneous needle biopsy was performed if possible. When CT scans were indeterminate for lesions, such as those smaller than $10 \mathrm{~mm}$, follow-up CT examinations were performed 3 months later (interim) to determine whether there were any interval changes in size, density, configuration, or internal structure. Annual CT examination (annual) was defined as CT scan every year. Thus, when growing tendency in the nodules was definitely identified at the annual

or interim repeat $\mathrm{CT}$ screen, surgical resection was also recommended if a 
diagnostic approach for the lesion was difficult. Clinical staging was evaluated by standard examination. All patients underwent physical examination, complete blood cell count, biochemistry examination, chest radiography, CT scans of the thorax and abdomen, bone scintigraphy, and magnetic resonance imaging (MRI) scan of the brain as pretreatment evaluation. Routine integrated positron emission tomography (PET)/CT scan was added to assess lymph node and distant involvement from 2005. Clinical and pathological staging were performed according to the 6th edition of the TNM classification of lung cancer [14]. Operative indication was considered for clinical stage IA - IIB in patients with preoperative diagnosis of SCLC. The classification of limited disease (LD) and extensive disease (ED) was based on the International Association for the Study of Lung Cancer (IASLC) criteria [15].

The survival of patients was calculated from the date of initial therapy until the time of death. Survival for all patients was recorded up to 31 September 2012. The actual overall survivals after initial treatment were calculated using the Kaplan-Meier method, and the differences in the resulting distributions were compared between groups by the log-rank test. Data were analyzed using the chi-square test and $P<0.05$ was taken to indicate statistical significance. 


\section{Results}

\section{Baseline characteristics}

The general characteristics of the 12 subjects are shown in Table 1 . The study population consisted of one female patient and 11 men (91.7\% male), with a mean age of 67.8 years old ranging from 51 to 82 years old. The female patient was a never-smoker, but the others were smokers with a mean number of pack-years of 42.2 \pm 4.3. Ten patients had performance status (PS) of $0(82.4 \%)$ and two had PS of 2 according to the Eastern Cooperative Oncology Group scale. The clinical characteristics, treatments, and outcomes in each case are shown according to the clinical stage of LD and ED (Table 2). Clinical stages of LD and ED were observed in nine and three patients, respectively. The frequency of LD in CT screening test (75\%, 9 of 12 cases) was significantly higher than that in other detected SCLC, such as symptomatic et al. $(42.6 \%, 58$ of 136 cases, $P<0.05)$. One patient with interstitial pneumonia (case 4) presented with shortness of breath, but none of the patients had specific symptoms of thoracic malignancy. In LD subjects, 5 cases underwent thoracic surgery. Among them, three patients (cases 1, 3, and 5) were not confirmed histologically to be malignant on preoperative evaluation, but surgical resection was recommended because annual or repeated CT findings on the target lesion revealed interval growing tendency. The pathological staging following surgery was inconsistent with clinical stage except in case 1 . In addition, partial resection was performed in cases 4 and 5 because of poor pulmonary 
function and pleural dissemination, respectively. The frequency of thoracic surgery as initial treatment in $\mathrm{CT}$ screening test $(41.7 \%, 5$ of 12 cases) was significantly higher than that in other detected $\operatorname{SCLC}(8.1 \%, 11$ of 136 cases, $P<0.01)$. Two to four cycles of postoperative chemotherapy were performed except in one patient (case 4). This case was associated with interstitial pneumonitis and considered unsuitable for chemotherapy. In the LD group, chemotherapy alone was selected in three patients because of association of chronic obstructive pulmonary disease (COPD) (case 6) and interstitial pneumonia (case 8), and concurrent thoracic radiotherapy was avoided in case 9 because of the extended chest field. In the ED group, standard chemotherapy was performed in two patients. In case 12 , the patient was 82 years old and refused chemotherapy; this patient died 9 months after diagnosis.

Survival analysis

The overall survival curve of the 12 cases is shown in Figure 1. Median survival time (MST) was 20.0 months (95\% confidence interval (CI): 15.6 - 24.4)(Figure 1). MST in non-CT-detected patients with SCLC in our institute $(n=136)$ was 14.0 months (95\% CI: $12-17)$ and was not significantly different from survival in CT-detected patients (data not shown). The survival periods according to the LD and ED classification are shown in Figure 2. The survival in LD patients (25.0 months, 95\% CI; $17.0-32.9$ ) was significantly longer than that in ED patients (16.0 months, 95\% CI: not evaluated). We analyzed the survival in patients 
initially treated with thoracic surgery and found no significant differences in survival between operated (MST; 27.0 months, 95\% CI; 16.4-144.4) and non-operated patients (MST;16.0, 95\% CI; $11.9-22.5, P=0.076)$. 


\section{Discussion}

We summarized the clinical characteristics, treatment and outcomes in 12 patients with SCLC detected by low-dose chest CT screening test at our institute. The frequency of LD and further early-stage patients who were suitable for thoracic surgery in CT-detected SCLC were significantly higher than those in the non-CT screening group. However, the MST of 20.0 months in the 12 subjects was not appreciably different from those in the non-CT screening group or reported for SCLC in general clinical practice [16-18].

A prospective study by NLST for lung cancer screening using chest CT demonstrated a decreased lung cancer-specific mortality in a CT screening population [6,7]. In contrast, the randomized Danish Lung Cancer Screening Trial (DLCST) failed to demonstrate improved mortality rates in almost the same population as NLST [19]. Thus, the contribution of low-dose CT screening to a decrease in lung cancer mortality remains undetermined. In general, SCLC is considered an inappropriate screening target due to its aggressive natural biology and early dissemination. As our results were based on the retrospective findings and non-randomized screening participation, we are unable to comment on the role of low-dose CT screening for SCLC. However, our results suggest that CT screening can detect early-stage SCLC and may shift the early stage distribution of SCLC, in contrast to the findings of Cuffe et al. [11]. 
Our results indicated no improvement of survival in patients with 12 SCLC patients compared with non-CT-detected patients. In addition, survival periods in LD and ED in our series seemed to be identical to those in SCLC patients with usual care detection [16-18]. Therefore, we suggest that CT screening could contribute little to improve survival outcome in patients with SCLC.

Several recent retrospective analyses have described improved or favorable survival rates in patients with resected SCLC [20-25]. Lim et al. [20] recently described excellent results, with a 5-year survival rate of $52 \%$ for patients with stage I- III disease who underwent lung resection. In Japanese subjects with resected SCLC, 5-year survival rate was $43 \%$, and survival has improved over the past several decades [21].Thus, surgery was associated with improved survival for selected patients with early-stage SCLC [20-25]. Indeed, two patients achieved long-term survival after surgery (cases 1 and 2) in the present analysis. Thus, CT screening may be beneficial in certain patients with SCLC at a curable stage. On the other hand, we found underestimation of $\mathrm{T}$ factor and clinical $\mathrm{T} 1$ stage changed to T4 due to pleural dissemination in two of the resected patients. Clinical and pathological differences were reported previously in resected patients with SCLC [23,24]. Surgical indication and evaluation for the operability in patients with early-stage SCLC are important.

With regard to the radiological features on CT in the early stages of SCLC, small nodules exhibiting well-defined and distinctly lobulated margins with rapid growth 
were characteristically shown [9,13,26]. Sone et al. [9] described the CT appearance in peripheral early-stage of SCLC; the lesions were typically spindleor pyramidal-shaped in the early phase, and later appeared as vermiform or tandem-like nodular lesions. In addition, the tumor growth was along the long axis of the bronchial wall in the lung periphery. They emphasized that the growing tendency on serial CT test was important at annual repeated or interim CT scan. In the present analysis, seven subjects were detected by interim and annual repeated CT examinations, and all cases were in LD stage. Thus, we would like to emphasize that initial assessment for a soft tissue density nodule on CT screening is essential, and interim or annual CT scanning of the nodule is useful for detecting further early-stage SCLC, compared with cases presenting clinical symptoms.

There were several limitations in the present study. First, CT screening was performed in a non-randomized manner, and entry criteria for CT screening subjects were not definite except age $>40$ years old. The upper age limit, cigarette history, and underlying baseline diseases, etc., were not prescribed for the CT screening test. Indeed, two patients in the present analysis were over 75 years old, while such elderly patients were not included in NLST [7] and DLCST [19] trials. In addition, three patients in the present study had preceding respiratory diseases, including COPD and interstitial pneumonia, which were risk factors for lung cancer. The concomitant diseases may affect the subsequent treatment strategy and/or prognosis of SCLC. Second, the number of patients with SCLC in the present study was small, which adversely affects evaluation of the clinical characteristics and 
outcomes. However, Cuffe et al. [11] summarized 10 cases with SCLC detected by CT screening and concluded the ineffectiveness of CT screening test. Thus, further studies to examine the usefulness of CT screening are needed.

In summary, in a retrospective analysis of 12 patients with SCLC detected by CT screening, we demonstrated that LD stage was prominent (9 cases) and early-stage SCLC suitable for thoracic surgery was observed in 5 patients. However, the overall survival periods in LD and ED stages were 25 and 16.0 months, respectively, which were identical to those in general clinical practice for SCLC. Our results suggest that $\mathrm{CT}$ screening test contributes to detection of early-stage SCLC, but it remains unclear whether this can improve clinical outcome in patients with SCLC.

\section{Conflict of interest}

None 


\section{References}

1. Dubey S, Powell CA. Update in lung cancer 2008. Am J Respir Crit Care Med. 2009; 179:860-868.

2. Matsuda T, Marugame T, Kamo K, Katanoda K, Ajiki W, Sobue T. The Japan Cancer Surveillance Research Group. Cancer Incidence and Incidence Rates in Japan in 2005: Based on Data from 12 Population-based Cancer Registries in the Monitoring of Cancer Incidence in Japan (MCIJ) Project. Jpn J Clin Oncol. 2011;41: 139-147.

3. Govindan R, Page N, Morgensztern D, Read W, Tierney R, Vlahiotis A, Spitznagel EL, Piccirillo J. Changing epidemiology of small-cell lung cancer in the United States over the last 30 years: analysis of the surveillance, epidemiologic, and end results database. $\mathbf{J}$ Clin Oncol. 2006;24:4539-4544.

4. Church TR. Chest radiography as the comparison for spiral CT in the National Lung Screening Trial. Acad Radiol. 2003;10:713-715.

5. Kaneko M, Eguchi K, Ohmatsu H, Kakinuma R, Naruke T, Suemasu K, Moriyama N. Peripheral lung cancer: screening and detection with low-dose spiral CT versus radiography. Radiology. 1996;201:798-802.

6. National Lung Screening Trial Research Team, Aberle DR, Adams AM, Berg CD, Black WC, Clapp JD, Fagerstrom RM, Gareen IF, Gatsonis C, Marcus PM, Sicks JD. Reduced lung-cancer mortality with low-dose computed tomographic screening. N Engl J Med. $2011 ; 365: 395-409$.

7. Patz EF Jr, Caporaso NE, Dubinett SM, Massion PP, Hirsch FR, Minna JD, Gatsonis C, Duan F, Adams A, Apgar C, Medina RM, Aberle DR. National Lung Cancer Screening 
Trial American College of Radiology Imaging Network Specimen Biorepository originating from the Contemporary Screening for the Detection of Lung Cancer Trial (NLST, ACRIN 6654): design, intent, and availability of specimens for validation of lung cancer biomarkers. J Thorac Oncol. 2010;5:1502-1506.

8.Sone S, Takashima S, Li F, Yang Z, Honda T, Maruyama Y, Hasegawa M, Yamanda T, Kubo K, Hanamura K, Asakura K. Mass screening for lung cancer with mobile spiral computed tomography scanner. Lancet. 1998;351:1242-1245.

9. Sone S, Nakayama T, Honda T, Tsushima K, Li F, Haniuda M, Takahashi Y, Hanaoka T, Takayama F, Koizumi T, Kubo K, Yamanda T, Kondo R, Fushimi H, Suzuki T. CT findings of early-stage small cell lung cancer in a low-dose CT screening programme. Lung Cancer. 2007;56:207-215.

10. Kondo R, Yoshida K, Kawakami S, Shiina T, Kurai M, Takasuna K, Yamamoto H, Koizumi T, Honda T, Kubo K. Different efficacy of CT screening for lung cancer according to histological type: Analysis of Japanese-smoker cases detected using a low-dose CT screen. Lung Cancer. 2011;74:433-440.

11. Cuffe S, Moua T, Summerfield R, Roberts H, Jett J, Shepherd FA. Characteristics and outcomes of small cell lung cancer patients diagnosed during two lung cancer computed tomographic screening programs in heavy smokers. J Thorac Oncol. 2011;6:818-22.

12. Takashima S, Sone S, Li F, Maruyama Y, Hasegawa M, Kadoya M. Indeterminate solitary pulmonary nodules revealed at population-based CT screening of the lung: using first follow-up diagnostic CT to differentiate benign and malignant lesions. Am J Roentgenol. $2003 ; 180: 1255-1263$. 
13. Hasegawa M, Sone S, Takashima S, Li F, Yang ZG, Maruyama Y, Watanabe T. Growth rate of small lung cancers detected on mass CT screening. Br J Radiol. 2000;73:1252-1259.

14. Sobin LH, Wittekind Ch (eds): International Union Against Cancer (UICC): "TNM classification of malignant tumors." 6th ed. New York: Wiley; 2002.

15. Stahel RA, Ginsberg R, Havemann K, Hirsch FR, Ihde DC, Jassem J, Karrer K, Maurer LH, Osterlind K, Houtte PV. Staging and prognostic factors in small cell lung cancer; a consensus report. Lung Cancer. 1989;5: 119-126.

16. Spigel DR. Treatment update in small-cell lung cancer: from limited to extensive disease. Curr Treat Options Oncol. 2012;13:505-515.

17. Albain KS, Crowley JJ, LeBlanc M, Livingston RB.Determinants of improved outcome in small-cell lung cancer: an analysis of the 2,580-patient Southwest Oncology Group data base. J Clin Oncol. 1990;8:1563-1574.

18. Shepherd FA, Crowley J, Van Houtte P, Postmus PE, Carney D, Chansky K, Shaikh Z, Goldstraw P; International Association for the Study of Lung Cancer International Staging Committee and Participating Institutions. The International Association for the Study of Lung Cancer lung cancer staging project: proposals regarding the clinical staging of small cell lung cancer in the forthcoming (seventh) edition of the tumor, node, metastasis classification for lung cancer. J Thorac Oncol. 2007;2:1067-77.

19.Saghir Z, Dirksen A, Ashraf H, Bach KS, Brodersen J, Clementsen PF, Døssing M, Hansen H, Kofoed KF, Larsen KR, Mortensen J, Rasmussen JF, Seersholm N, Skov BG, Thorsen H, Tønnesen P, Pedersen JH. CT screening for lung cancer brings forward early disease. The 
randomized Danish Lung Cancer Screening Trial: status after five annual screening rounds with low-dose CT. Thorax. 2012;67:296-301.

20.Lim E, Belcher E, Yap YK, Nicholson AG, Goldstraw P. The role of surgery in the treatment of limited disease small cell lung cancer: time to reevaluate. J Thorac Oncol. 2008;3:1267-1271.

21.Koike T, Yamato Y, Asamura H, Tsuchiya R, Sohara Y, Eguchi K, Mori M, Nakanishi Y, Goya T, Koshiishi Y, Miyaoka E; Japanese Joint Committee for Lung Cancer Registration. Improvements in surgical results for lung cancer from 1989 to 1999 in Japan. J Thorac Oncol. 2009;4:1364-1369.

22. Schreiber D, Rineer J, Weedon J, Vongtama D, Wortham A, Kim A, Han P, Choi K, Rotman M. Survival outcomes with the use of surgery in limited-stage small cell lung cancer: should its role be re-evaluated? Cancer. 2010;116:1350-1357.

23. Vallières E, Shepherd FA, Crowley J, Van Houtte P, Postmus PE, Carney D, Chansky K, Shaikh Z, Goldstraw P;International Association for the Study of Lung Cancer International Staging Committee and Participating Institutions. The IASLC Lung Cancer Staging Project: proposals regarding the relevance of TNM in the pathologic staging of small cell lung cancer in the forthcoming (seventh) edition of the TNM classification for lung cancer. J Thorac Oncol. 2009;4:1049-1059.

24. Inoue M, Miyoshi S, Yasumitsu T, Mori T, Iuchi K, Maeda H, Matsuda H. Surgical results for small cell lung cancer based on the new TNM staging system. Thoracic Surgery Study Group of Osaka University, Osaka, Japan. Ann Thorac Surg. 2000;70:1615-1619.

25. Shepherd FA, Ginsberg RJ, Feld R, Evans WK, Johansen E. Surgical treatment for limited 
small-cell lung cancer. The University of Toronto Lung Oncology Group experience. J Thorac Cardiovasc Surg. 1991;101:385-393.

26. Wang JC, Sone S, Feng L, Yang ZG, Takashima S, Maruyama Y, Hasegawa M, Kawakami S, Honda T, Yamanda T. Rapidly growing small peripheral lung cancers detected by screening CT: correlation between radiological appearance and pathological features. $\mathrm{Br} \mathrm{J}$ Radiol. 2000;73: 930-937. 
Table 1

General patient's characteristics $(n=12)$

\begin{tabular}{|c|c|}
\hline $\begin{array}{c}\text { Mean age } \\
\text { (range) }\end{array}$ & $\begin{array}{c}67.8 \mathrm{yrs} \\
(51-82)\end{array}$ \\
$\begin{array}{c}\text { Gender } \\
\text { (Male/Female) }\end{array}$ & $11 / 1$ \\
\hline $\begin{array}{c}\text { Mean pack years } \\
\text { (range) }\end{array}$ & $\begin{array}{c}42.2 \\
(0-80)\end{array}$ \\
\hline $\begin{array}{c}\text { Performance Status } \\
0 / 1 / 2\end{array}$ & $10 / 0 / 2$ \\
\hline $\begin{array}{c}\text { Stage } \\
\text { Limited / Extensive disease }\end{array}$ & $9 / 3$ \\
\hline
\end{tabular}


Table 2

Clinical characteristics, treatment, and outcomes in patients with small cell lung cancer detected by CT screening $(n=12)$

\begin{tabular}{|c|c|c|c|c|c|c|c|c|c|}
\hline & Case & $\begin{array}{c}\text { CT of } \\
\text { detection }\end{array}$ & $\begin{array}{l}\text { Clinical TNM } \\
\text { (Pathological) }\end{array}$ & $\begin{array}{l}\text { Preoperative } \\
\text { diagnosis }\end{array}$ & 1 st treatment & 2nd treatment & $\begin{array}{l}\text { Survival } \\
\text { (months) }\end{array}$ & Outcome & Complications \\
\hline \multirow[t]{9}{*}{$\begin{array}{l}\text { Limited } \\
\text { disease }\end{array}$} & 1 & Annual & $\begin{array}{l}\text { T1NOMO } \\
\text { (T1NOMO) }\end{array}$ & $(-)$ & lobectomy & $\begin{array}{c}\text { adjuvant } \\
\text { CAV/CDDP+VP-16 }\end{array}$ & 178 & alive & \\
\hline & 2 & Baseline & $\begin{array}{l}\text { T2NOMO } \\
\text { (T1N1M0) }\end{array}$ & $(+)$ & lobectomy & $\begin{array}{c}\text { adjuvant } \\
\text { CAV/CDDP+VP-16 }\end{array}$ & 161 & dead & \\
\hline & 3 & Interim & $\begin{array}{l}\text { T1NOMO } \\
\text { (T4NOMO) }\end{array}$ & $(-)$ & lobectomy & $\begin{array}{c}\text { adjuvant } \\
\text { CDDP+CPT-11 }\end{array}$ & 27 & dead & \\
\hline & 4 & Annual & $\begin{array}{l}\text { T1N1M0 } \\
\text { (T1NOMO) }\end{array}$ & $(+)$ & partial resection & $(-)$ & 19 & dead & $\begin{array}{l}\text { Interstitial } \\
\text { pneumonia }\end{array}$ \\
\hline & 5 & Annual & $\begin{array}{l}\text { T1N1M0 } \\
\text { (T4N2M0) }\end{array}$ & $(-)$ & segmentectomy & $\begin{array}{c}\text { adjuvant } \\
\text { CAV/CDDP+VP-16 }\end{array}$ & 17 & dead & \\
\hline & 6 & Annual & T2N1M0 & & $C B D C A+C P T-11$ & $(-)$ & 25 & dead & COPD \\
\hline & 7 & Interim & T4N2MO & & $\begin{array}{l}\text { CDDP+VP16 } \\
+ \text { conRT }\end{array}$ & $\mathrm{CDDP}+\mathrm{CPT}-11$ & 20 & dead & \\
\hline & 8 & Baseline & T3N2MO & & $\mathrm{CDDP}+\mathrm{VP} 16$ & amrubicin & 11 & alive & $\begin{array}{l}\text { Interstitial } \\
\text { pneumonia }\end{array}$ \\
\hline & 9 & Interim & T2N2MO & & $\mathrm{CDDP}+\mathrm{CPT}-11$ & $\mathrm{CBDCA}+\mathrm{VP} 16$ & 10 & dead & \\
\hline \multirow[t]{4}{*}{$\begin{array}{c}\text { Extensive } \\
\text { disease }\end{array}$} & & & $\begin{array}{c}\text { Clinical TNM } \\
\text { (Metastatic sites) }\end{array}$ & & & & & & \\
\hline & 10 & Baseline & $\begin{array}{c}\text { T1 N0M1 } \\
\text { (PUL, HEP) }\end{array}$ & & $\mathrm{CBDCA}+\mathrm{VP} 16$ & $\mathrm{CBDCA}+\mathrm{CPT}-11$ & 16 & dead & \\
\hline & 11 & Baseline & $\begin{array}{c}\text { T4N3M1 } \\
\text { (PLE、HEP) }\end{array}$ & & $\mathrm{CDDP}+\mathrm{CPT}-11$ & $\mathrm{CDDP}+\mathrm{VP} 16$ & 14 & alive & \\
\hline & 12 & Baseline & $\begin{array}{c}\text { T1N3M0 } \\
\text { (cervical LYM) }\end{array}$ & & BSC & $(-)$ & 9 & dead & \\
\hline
\end{tabular}

Baseline: initial CT scan, Interim: repeated CT scan 3-6 months after the initial CT, Annual: CT scan every year. CDDP:cisplatin, CBDCA:Carboplatin, CPT-11:Irinotecan, VP16:etoposide, conRT:concurrent thoracic radiotherapy. CAV : cyclophosphamide, doxorubicin, vincristine, BSC : Best supportive care 


\section{Figure Legends}

Figure 1

A. Overall survival in patients with small cell lung cancer detected by low-dose

computed tomography screening.

B. Comparative analysis of survival according to a classification of limited disease

(LD) and extensive disease (ED) in patients with small cell lung cancer detected by

low-dose computed tomography screening. The survival period in LD (median

survival $=25.0$ months, $95 \%$ CI $17.0-32.9)$ was significantly longer than that in

ED $($ median survival $=16.0$ months, $95 \%$ CI not evaluated $)$. 


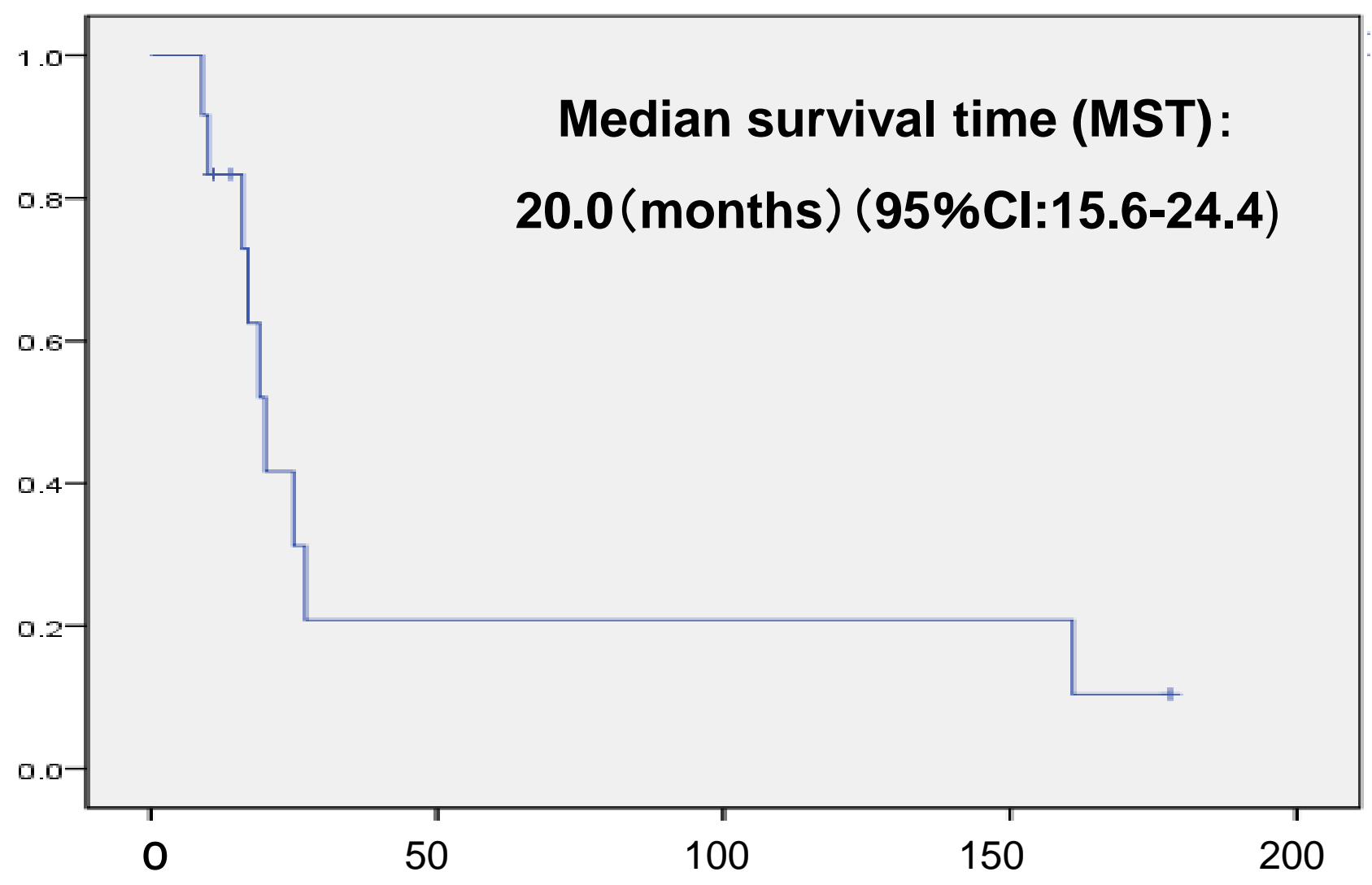

survival (months)

Figure 1 


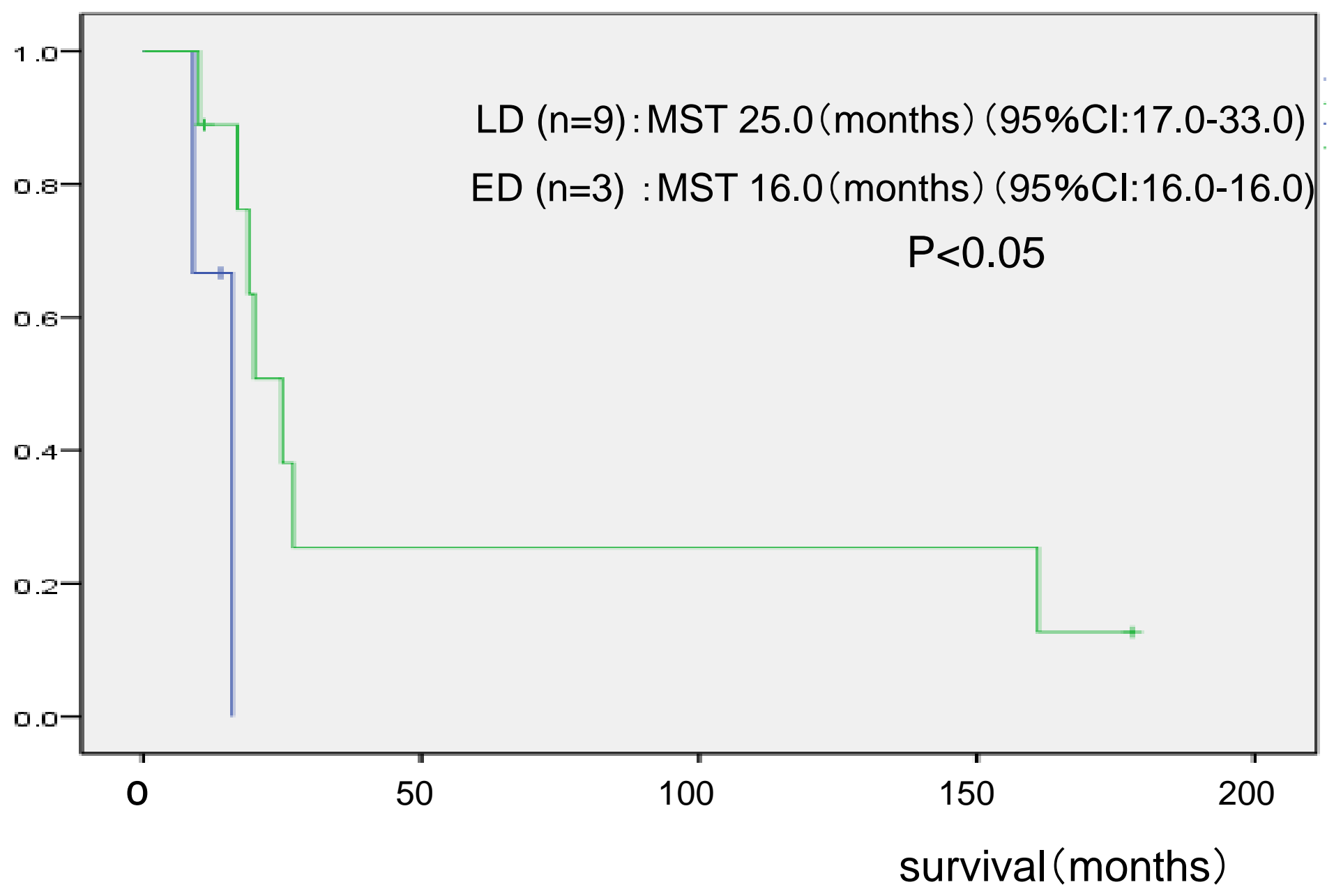

Figure 2 